\title{
Tfap2a and $2 b$ act downstream of Ptf1a to promote amacrine cell differentiation during retinogenesis
}

\author{
Kangxin Jin ${ }^{1 \dagger}$, Haisong Jiang ${ }^{2,4 \dagger}$, Dongchang Xiao ${ }^{1}$, Min Zou ${ }^{2}$, Jun Zhu ${ }^{3}$ and Mengqing Xiang ${ }^{1,2^{*}}$
}

\begin{abstract}
Retinogenesis is a precisely controlled developmental process during which different types of neurons and glial cells are generated under the influence of intrinsic and extrinsic factors. Three transcription factors, Foxn4, ROR $\beta 1$ and their downstream effector Ptf1a, have been shown to be indispensable intrinsic regulators for the differentiation of amacrine and horizontal cells. At present, however, it is unclear how Ptf1a specifies these two cell fates from competent retinal precursors. Here, through combined bioinformatic, molecular and genetic approaches in mouse retinas, we identify the Tfap2a and Tfap2b transcription factors as two major downstream effectors of Ptf1a. RNA-seq and immunolabeling analyses show that the expression of Tfap2a and $2 \mathrm{~b}$ transcripts and proteins is dramatically downregulated in the Ptfla null mutant retina. Their overexpression is capable of promoting the differentiation of glycinergic and GABAergic amacrine cells at the expense of photoreceptors much as misexpressed Ptf1a is, whereas their simultaneous knockdown has the opposite effect. Given the demonstrated requirement for Tfap2a and $2 b$ in horizontal cell differentiation, our study thus defines a Foxn4/RORß1-Ptf1a-Tfap2a/2b transcriptional regulatory cascade that underlies the competence, specification and differentiation of amacrine and horizontal cells during retinal development.
\end{abstract}

Keywords: Tfap2, Ptf1a, Foxn4, Amacrine cell, Horizontal cell, Retinal development

\section{Introduction}

In the mammalian retina, there are six major types of neurons, including ganglion, amacrine, horizontal, bipolar, cone and rod cells. During retinogenesis, the generation of proper quantity and types of these neurons in the correct position at the right time is essential for the assembly of a fully functional retina. This developmental process is primarily controlled by intrinsic programs coded largely by transcription factors, as well as influenced by various extrinsic factors such as hormones, cytokines, chemokines, cell-cell interactions, and so on [1-4].

\footnotetext{
*Correspondence: xiang@cabm.rutgers.edu

${ }^{\dagger}$ Equal contributors

'State Key Laboratory of Ophthalmology, Zhongshan Ophthalmic Center, Sun Yat-sen University, 54 South Xianlie Road, Guangzhou 510060, China ${ }^{2}$ Center for Advanced Biotechnology and Medicine and Department of Pediatrics, Rutgers University-Robert Wood Johnson Medical School, 679 Hoes Lane West, Piscataway, NJ 08854, USA

Full list of author information is available at the end of the article
}

The amacrine, horizontal and bipolar cells in the retina are interneurons that serve to relay, integrate and modulate visual signals from photoreceptors to ganglion cells. The amacrine cells, which modulate synaptic activity between bipolar and ganglion cells, are the most diverse cell type within the retina $[5,6]$. In mammals, they can be classified into at least 28 different subtypes based on criteria such as morphology, sublaminar location, and neurotransmitter types (e.g. glycinergic, GABAergic, dopaminergic or cholinergic) $[7,8]$. Glycinergic amacrine cells are usually small-field neurons with diffuse dendritic trees $[9,10]$, whereas GABAergic amacrine cells generally have wider dendritic fields than those of glycinergic cells [11,12]. Horizontal cells constitute a class of retinal interneurons that modulate signal transmission between photoreceptors and bipolar cells.

Although a few intrinsic and extrinsic factors have been identified that affect amacrine and horizontal cell development, the genetic regulatory network that controls their determination and differentiation remains to

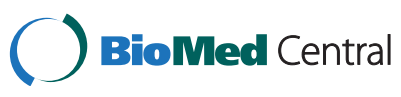


be defined. Ablation of Foxn4 in mice causes a loss of all horizontal cells and the great majority of amacrine cells. Conversely, its misexpression in mouse and chick retinas promoted the amacrine and horizontal cell fates $[13,14]$. Gene expression profiling identified Ptfla as one of the most downregulated genes in Foxn4 null mutant retinas, and in Ptf1a mutants, there is similar loss of all horizontal cells and the majority of amacrine cells; however, there is no change in Foxn4 expression $[15,16]$, thereby defining a Foxn4-Ptf1a pathway controlling the specification of amacrine and horizontal cells $[4,15,17]$. Indeed, Ptf1a overexpression has been shown to promote amacrine and horizontal cell differentiation in the chick, Xenopus and zebrafish [18-20]. This pathway has been expanded recently to include the retinoid-related orphan receptor isoform $\beta 1$ (ROR $\beta 1$ ), whose inactivation phenocopies the Foxn 4 and Ptfla mutants in amacrine and horizontal cell development and downregulates the expression of Ptfla but not Foxn4 [21]. It seems that ROR $\beta 1$ acts in parallel with Foxn4 to activate Ptfla expression [21]. At present, it is unclear what are the Ptf1a downstream effectors that mediate its function during retinal cell development.

We provide evidence in this study that Tfap2a and Tfap2b are positioned downstream of Ptf1a in the transcription factor pathway governing amacrine and horizontal cell development. These two factors belong to the Activating Enhancer Binding Protein 2 family, for which currently at least five members $(2 \mathrm{a} / \alpha, 2 \mathrm{~b} / \beta, 2 \mathrm{c} / \gamma, 2 \mathrm{~d} / \delta, 2 \mathrm{e} /$ $\varepsilon)$ have been identified. Tfap $2 \mathrm{a}$ and $2 \mathrm{~b}$ recognize and bind to the consensus sequence 5'-GCCNNNGGC-3' and activate genes involved in a large spectrum of important biological functions including eye, neural tube, ear, kidney, and limb development [22,23]. Mutations in human TFAP2A are associated with the Branchio-Oculo-Facial Syndrome $[24,25]$. In the early retina, both Tfap2a and $2 \mathrm{~b}$ are expressed in the developing amacrine and horizontal cells and conditional ablation of Tfap $2 a$ alone is insufficient to cause any defect in either cell population [26-28]. However, a double mutant lost all of the horizontal cells but displayed no obvious change in the number of amacrine cells except for a minor migratory defect [28], suggesting that Tfap2a and $2 \mathrm{~b}$ are redundantly required for horizontal cell differentiation but may be nonessential for amacrine cell differentiation. Here, however, we provide RNA-seq evidence to position Tfap $2 a$ and $2 b$ downstream of Ptfla, and demonstrate that they can mediate the crucial function of Ptfla in amacrine cell development, using both gain- and loss-of-function approaches.

\section{Results}

Tfap $2 a$ and $2 b$ are genetically downstream of the Foxn4Ptf1a pathway

To explore the molecular basis by which Ptfla controls amacrine and horizontal cell development, we carried out RNA-seq analysis to identify genes differentially expressed in Ptfla mutant retinas. RNA was extracted from $\mathrm{Ptfla}^{+/+}$and $\mathrm{Ptf1} a^{\mathrm{Cre} / \mathrm{Cre}}$ retinas at E14.5 when amacrine and horizontal cells are being born and Ptf1a function is required. This analysis yielded 224 genes whose expression level is downregulated or upregulated by 2 -fold or more in the mutant retina (Figure 1A, B; Additional file 1: Table S1). These include genes encoding transcription factors, G-protein coupled receptors, kinases and transporters, etc. (Figure 1C). Consistent with the crucial role of Ptf1a in retinal development, we found that the differentially expressed genes are enriched with GO (Gene Ontology) terms such as positive regulation of neurogenesis, nervous system development, tissue development, cellular component morphogenesis, response to extracellular stimulus, transcription factor activity, and so on (Figure 1D).

Among the genes differentially expressed in Ptf1a null mutant retinas, transcription factor genes constitute one of the largest functional groups (Figure 1C). These include Tfap $2 a$ and Tfap $2 b$, which are downregulated by 4- and 13-fold, respectively (Figure 1E; Figure 2A). Similarly, our previous microarray data show that these two genes are downregulated by 4- and 9-fold, respectively, in the E14.5 Foxn4 null retina [29]. To confirm the RNA-seq data, we measured RNA levels of these two genes in E14.5 wild type and Ptf1a ${ }^{\mathrm{Cre} / \mathrm{Cre}}$ retinas by semi-quantitative RT-PCR, and found that there was a dramatic decrease in Tfap $2 a$ and $2 b$ transcripts in the null retina compared to the control (Figure 2B). In addition, we examined Tfap $2 \mathrm{a}$ and $2 \mathrm{~b}$ protein expression levels by immunofluorescence using two antibodies, one of which cross-reacts with both proteins and the other is specific to Tfap2b. Either antibody barely detected any Tfap2a/2b-expressing cells in E16.5 and P0 Ptf1a null retinas despite plenty of them present in the control retina (Figure $2 \mathrm{C}-\mathrm{J}$ ).

During mouse retinal development, Tfap2b expression is barely detectable in E12.5 retinas but found in cells scattered within the central region of E13.5 retinas (Additional file 2: Figure S1A, B). From E14.5 to early postnatal stages, Tfap2b-expressing cells gradually concentrate into the presumptive inner nuclear layer (INL) (Additional file 2: Figure S1C, D; Figure 2G, I). In late postnatal and mature retinas, Tfap $2 \mathrm{~b}$ is expressed in numerous amacrine cells located within the inner half of the INL, in all horizontal cells residing at the outer plexiform layer, as well as in a subset of cells in the ganglion cell layer (GCL) (Additional file 2: Figure S1F). Moreover, Tfap2a and $2 \mathrm{~b}$ are colocalized in most of these cells although the expression of Tfap2a is rather weak in horizontal cells (Additional file 2: Figure S1E-G). A similar spatiotemporal expression pattern was previously reported for Tfap2a during mouse retinal development 


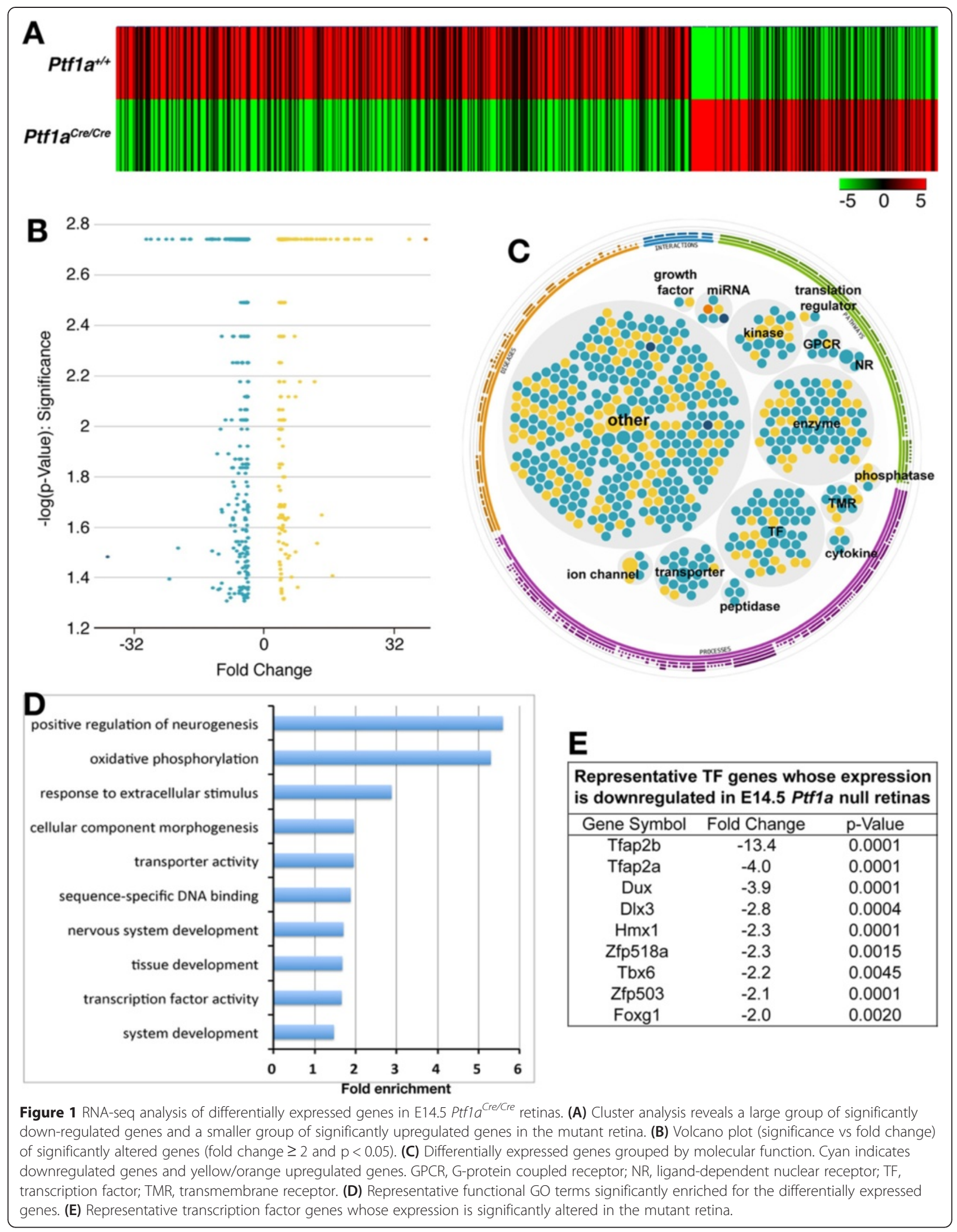




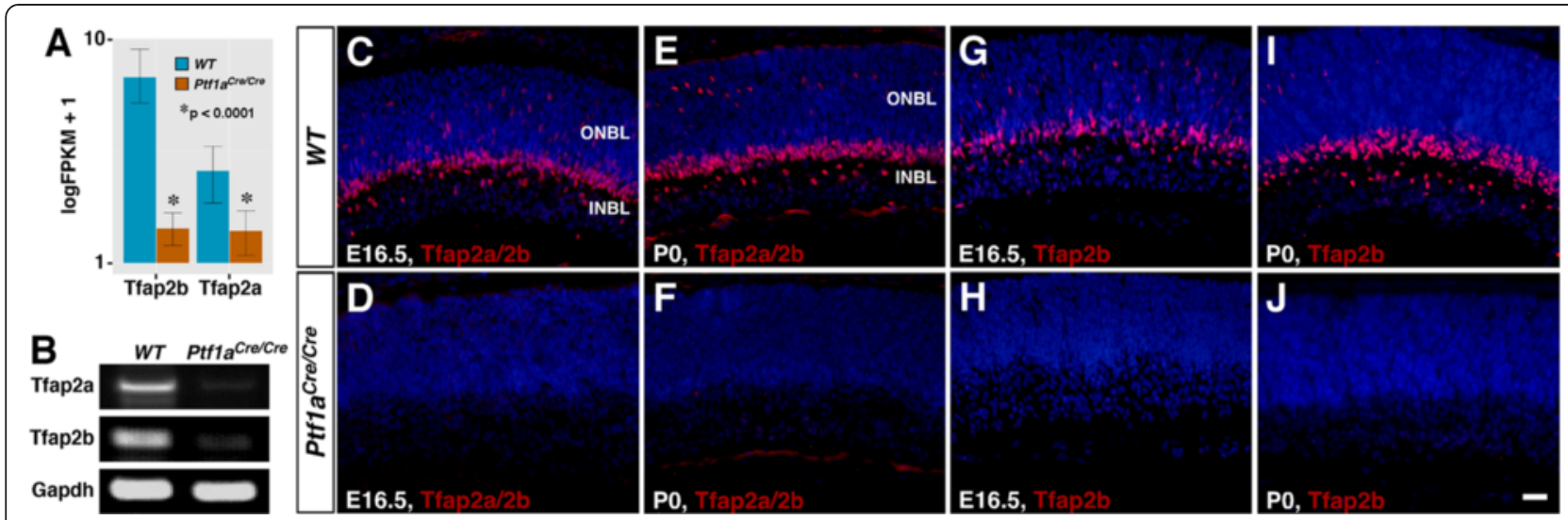

Figure 2 Downregulation of Tfap2a and 2b expression in Ptf1a mutant retinas. (A) Expression plot shows a dramatic reduction of Tfap2a and $2 b$ expression in the Ptf1a ${ }^{\text {Cre/Cre }}$ retina compared to the wild type (WT), as measured by FPKM. (B) Semiquantitative RT-PCR assay reveals a great decrease of Tfap $2 a$ and $2 b$ RNA levels in the null retina. Gapdh was used as an internal control to confirm that equal amount of cDNA was used for each sample. (C-J) Sections from E16.5 and PO retinas of Ptfl $a^{+/+}$and Ptfla ${ }^{\text {cre/cre }}$ mice were immunostained with antibodies that react with both Tfap2a and 2b (C-F) or only Tfap2b (G-J), and weakly counterstained with DAPI. There is almost a complete loss of Tfap2-immunoreactive cells in Ptfla $a^{\text {cre/cre }}$ retinas. Abbreviations: INBL, inner neuroblastic layer; ONBL, outer neuroblastic layer. Scale bar: C-J, 25 mm.

[26]. However, unlike Tfap2a and 2b, our previous study indicates that Ptf1a expression is limited to retinal precursor cells as its expression is transient, present only in the outer neuroblastic layer throughout development, and has an onset time of E12.5 [15]. These results combined with the RNA-seq data thus suggest that Tfap2a and 2b may function genetically downstream of the Foxn4-Ptfla pathway and have a role in amacrine and horizontal cell development.

\section{Ptf1a induces Tfap2b expression and promotes the amacrine and horizontal cell fates}

The drastic downregulation of Tfap $2 a$ and $2 b$ expression in Ptf1a null retinas suggest that Ptfla may act upstream of these two genes to activate their expression. We tested this possibility by overexpressing Ptf1a in the mouse retina using the pCIG expression vector carrying a GFP reporter [30-32]. pCIG-Ptf1a and pCIG plasmid DNA (Additional file 3: Figure S2A) was injected into the subretinal space of newborn mice and electroporated into the retina. At P12, we found that forced Ptf1a expression induced 2-fold more Tfap $2 b+$ cells in retinas transfected with the pCIGPtfla plasmid than in the control retina (Figure 3G, H, Y). Given that Ptf1a is able to induce Tfap2a expression in the chick retina [18], it appears that the expression of both Tfap $2 a$ and $2 b$ may be under positive regulation by Ptfla.

We further analyzed the laminar position and morphology of GFP+ cells in transfected retinas at P12. In retinas transfected with pCIG-Ptf1a DNA, the fraction of GFP+ cells differentiated as photoreceptors in the ONL (outer nuclear layer) dropped from $81.8 \%$ in the control retina to $63.5 \%$ (Additional file 3: Figure S2B-D). The percentage of GFP+ cells located in the outer half of the INL (inner nuclear layer) also decreased from $10.0 \%$ in the control to 1.3\% (Additional file 3: Figure S2B-D). In contrast, the proportion of GFP+ cells distributed within the inner half of the INL dramatically increased from $8.3 \%$ in the control to $35.2 \%$ (Additional file 3 : Figure S2B-D). Thus, Ptf1a misexpression substantially changes the proportions of progeny distributed in different retinal cell layers.

The increased GFP+ cells in the INL of retinas transfected with the pCIG-Ptfla plasmid displayed an amacrine cell morphology (Additional file 3: Figure S2C). Indeed, we found that ectopically expressed Ptfla obviously increased the number of GFP+ cells immunoreactive for Pax6, GLYT1, calretinin, or TH (tyrosine hydroxylase), all proteins expressed in amacrine cells (Figure 3A-F, O, P). Quantification of colocalized cells revealed that forced Ptfla expression dramatically increased the percentage of Pax6+ cells from $6.6 \%$ to $31.9 \%$, GLYT1+ cells from $4.0 \%$ to $27.4 \%$, calretinin + cells from $3.4 \%$ to $31.4 \%$, and $\mathrm{TH}+$ cells from $0.0 \%$ to $13.0 \%$ (Figure 3Y). Furthermore, smaller increase was observed in the number of GFP+ cells immunoreactive for GABA, Gad65, Gad67 and calbindin in retinas transfected with pCIG-Ptf1a DNA (Figure 3I-N, Q, R, $Y)$. On the other hand, misexpressed Ptfla decreased the percentage of GFP+ photoreceptor cells immunoreactive for recoverin from $81.8 \%$ to $63.5 \%$, GFP+ bipolar cells immunoreactive for Chx10 from $6.7 \%$ to $1.1 \%$, and Müller glial cells immunoreactive for GS (glutamine synthetase) from $3.3 \%$ to $0.0 \%$ (Figure 3S-Y). These data suggest that Ptfla is able to promote the differentiation of all kinds of amacrine cells including glycinergic, GABAergic and dopaminergic neurons at the expense of photoreceptor, bipolar and Müller cells.

To determine the effect of misexpressed Ptfla on development of horizontal and ganglion cells, which are born 

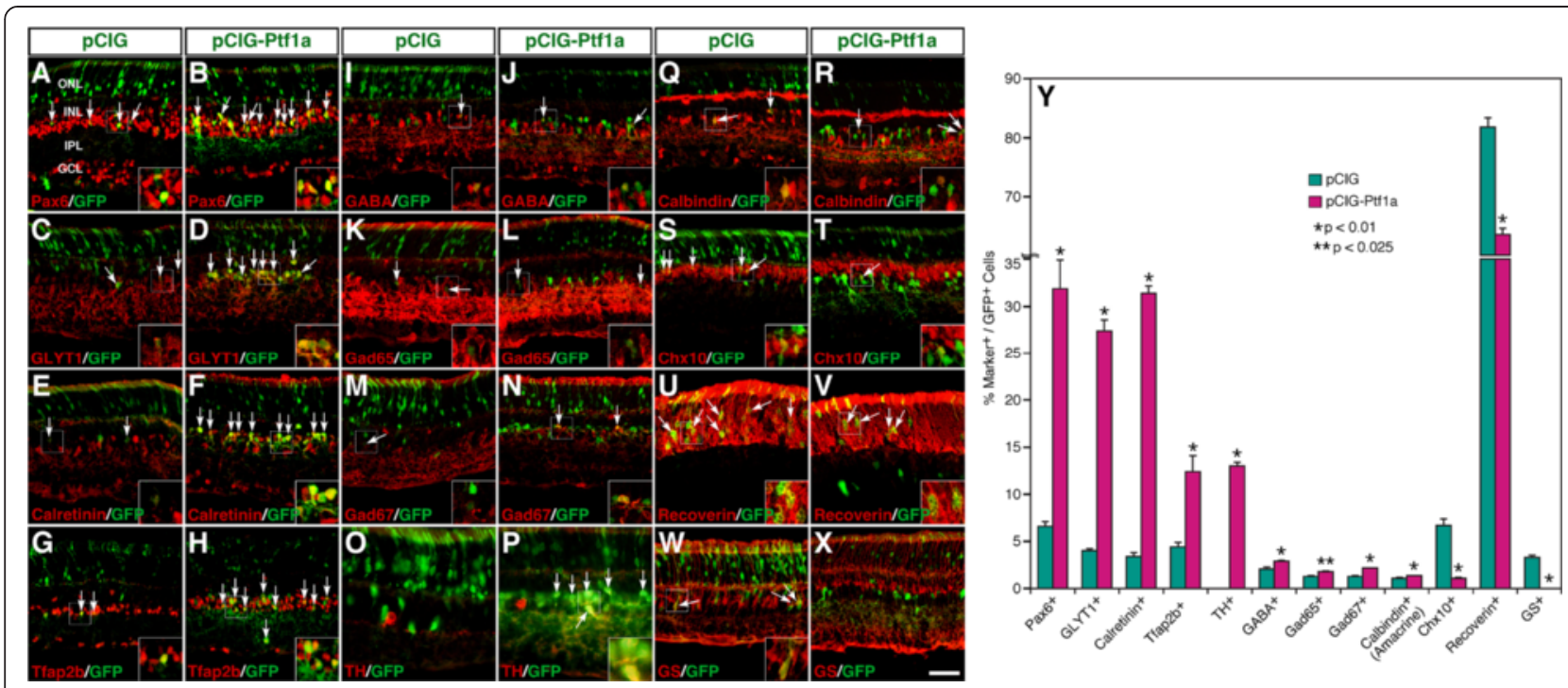

Figure 3 Effect of misexpressed Ptf1a on the formation of different retinal cell types. (A-X) Sections from retinas electroporated with pCIG or pCIG-Ptf1a DNA were double-immunostained with an anti-GFP antibody and antibodies against the indicated cell type-specific markers. Misexpressed Ptf1a resulted in overt increase in the number of amacrine cells immunoreactive for Pax6, GLYT1, calretinin, Tfap2b or TH (A-H, O, P), and smaller increase in the number of amacrine cells immunoreactive for GABA, Gad67, Gad65, or calbindin (I-N, Q, R). However, it suppressed the formation of bipolar cells immunoreactive for $\mathrm{Chx10}(\mathbf{S}, \mathbf{T})$, photoreceptor cells immunoreactive for recoverin $(\mathbf{U}, \mathbf{V})$, and Müller cells immunoreactive for GS (W, X). Arrows point to representative colocalized cells and insets show corresponding outlined regions at a higher magnification. (Y) Quantitation of GFP+ cells that become immunoreactive for a series of cell type-specific markers. Each histogram represents the mean \pm SD for three retinas. More than 500 GFP+ cells were scored in each retina. Abbreviations: GCL, ganglion cell layer; INL, inner nuclear layer; IPL, inner plexiform layer; ONL, outer nuclear layer. Scale bar: A-N, Q-T, W, X, $39.7 \mu \mathrm{m} ; \mathrm{O}, \mathrm{P}, 30.2 \mu \mathrm{m} ; \mathrm{U}, \mathrm{V}, 23.8 \mu \mathrm{m}$.

at embryonic stages, we used a replication-incompetent murine retroviral vector that carries a GFP reporter [33] to mediate Ptfla overexpression. E13.5 retinal explants were infected with Ptfla-GFP or Control-GFP viruses (Figure 4A), and the infected retinas were harvested after 4.5 days in culture to analyze horizontal and ganglion cells or collected after 12.5 days in culture for analysis of other cell types. We found that misexpressed Ptfla increased Lim1+ horizontal cells by approximately 25 -fold, decreased Brn3a + ganglion cells by 11 -fold, and similarly reduced Brn3b + ganglion cells (Figure 4B, I-N). It also significantly increased Pax6+, GLYT1+ and Gad67+ amacrine cells but reduced Chx10+ bipolar and GS+ Müller cells (Figure 4B-H), similar to its effect in retinas transfected at P0 (Figure 3). Therefore, these data suggest that Ptfla has the ability to not only promote the horizontal cell fate but also suppress the ganglion cell fate, in agreement with the finding in Ptfla null retinas [15,16].

\section{Tfap $2 b$ is expressed in amacrine and horizontal cells and promotes amacrine cell differentiation}

As a downstream transcription factor, Tfap2b may mediate in part the function of Ptf1a in amacrine and horizontal cell development. To test this possibility, we first comprehensively characterized the types and subtypes of Tfap2b-expressing cells in the mouse retina by immunofluorescence using a battery of cell type- and subtype- specific markers. Consistent with it being expressed in amacrine cells, there is extensive colocalization between Tfap2b and Pax6, syntaxin, GABA, GAD67, GAD65, Nr4a2, ChAT (choline acetyltransferase), GLYT1, Ebf, calbindin, calretinin, or TH (Figure 5A-E, G-K; Additional file 4: Figure S3A, B). Tfap2b appears also to be completely colocalized with calbindin and Lim1 in horizontal cells (Figure $5 \mathrm{~K}, \mathrm{~L}$; Additional file 4: Figure $\mathrm{S3H}$ ). There is no expression of Tfap $2 b$ in Brn3a + and Brn3b + ganglion cells, Chx10+ bipolar cells, recoverin + photoreceptors, and Sox9+ Müller cells (Additional file 4: Figure S3C-H). Consistent with this, Tfap2b is co-expressed with Bhlhb5 only in a small set of GABAergic amacrine cells since Bhlhb5 is additionally expressed in bipolar cells (Figure 5F; Additional file 4: Figure S3H). Quantification of colocalized amacrine cells revealed that the proportions of Tfap2b-expressing cells in all Pax6+, syntaxin + and GLYT1+ populations are $54.7 \%, 64.7 \%$ and $73.9 \%$, respectively (Additional file 4: Figure $\mathrm{S} 3 \mathrm{H}$ ), suggesting that Tfap $2 b$ is expressed in most but not all glycinergic amacrine cells. However, Tfap2b is expressed in $100 \%$ of GABA+, GAD67+, GAD65+, ChAT+, TH+, or Nr4a2+ cells, indicating that it may be expressed by all GABAergic amacrine cells including the starburst (marked by ChAT) and dopaminergic (marked by $\mathrm{TH}$ ) subtypes.

Tfap $2 \mathrm{~b}$ and $2 \mathrm{a}$ are reported to be redundantly required for horizontal cell generation but appear to be dispensable 


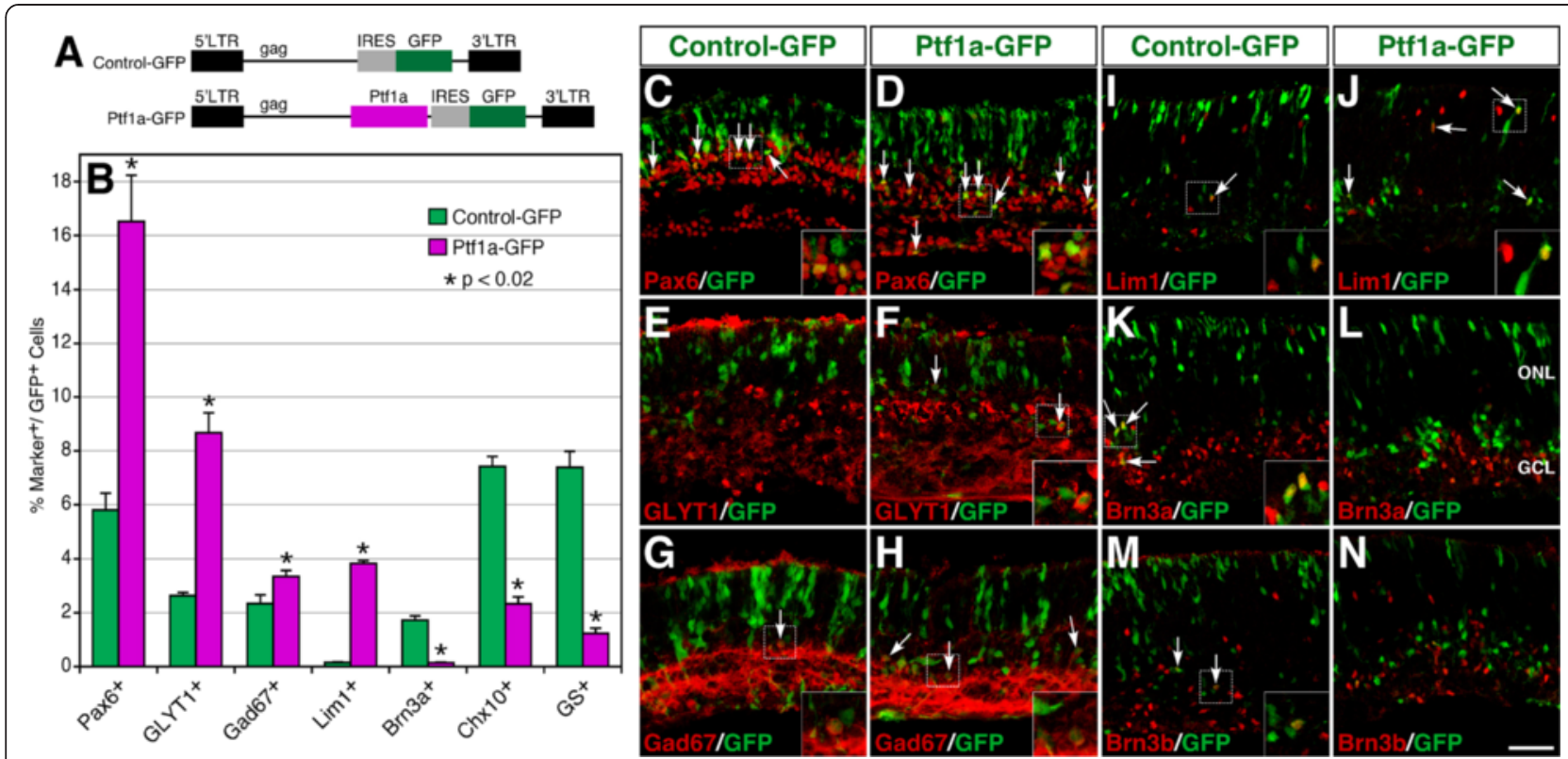

Figure 4 Effect of Ptf1a misexpressed at E13.5 on the formation of different retinal cell types. (A) Schematics of control-GFP and Ptf1a-GFP retroviral constructs. The internal ribosomal entry site (IRES) allows for efficient expression of both Ptf1a and GFP. (B) Quantitation of GFP+ cells that become immunoreactive for various cell type-specific markers. Each histogram represents the mean \pm SD for three retinas. More than 500 GFP+ cells were scored in each retina. (C-N) Sections from retinas infected with control-GFP or Ptf1a-GFP viruses were double-immunostained with an anti-GFP antibody and antibodies against the indicated cell type-specific markers. Forced Ptf1a expression in E13.5 retinas led to an increase in amacrine cells immunoreactive for Pax6, GLYT1 or GAD67 (C-H) and horizontal cells immunoreactive for Lim1 (I, J), but a decrease of ganglion cells immunoreactive for Brn3a or Brn3b (K-N). Arrows point to representative colocalized cells and insets show corresponding outlined regions at a higher magnification. Abbreviations: $\mathrm{GCL}$, ganglion cell layer; ONL, outer nuclear layer. Scale bar: I-N, $39.7 \mu \mathrm{m}$; C-H, $34 \mu \mathrm{m}$.

for generating amacrine cells [26,28]. We investigated whether Tfap $2 b$ has the ability to promote amacrine cell differentiation by overexpressing it in retinas of newborn mice via electroporation. In P12 transfected retinas, similar to Ptf1a (Additional file 3: Figure S2), we found that overexpressed Tfap $2 \mathrm{~b}$ increased GFP+ cells within the inner half of the INL by 2 -fold while significantly diminishing those in the ONL and slightly reducing those in the outer half of the INL (Additional file 5: Figure S4). There was an overt increase in the number of GFP+ cells immunoreactive for Pax6 and GLYT1 in retinas transfected with the pCIG-Tfap2b plasmid compared to the control (Figure 6A-D). Misexpressed Tfap2b increased the fraction of Pax6+ cells from $6.6 \%$ to $12.5 \%$ and GLYT1+ cells from $4.0 \%$ to $8.0 \%$ (Figure $6 \mathrm{U}$ ). It also resulted in smaller but significant increase in the proportion of calretinin+, GABA+, Gad65+, Gad67+ and calbindin + amacrine cells while significantly reducing the fraction of recoverin + photoreceptors (Figure 6E-J, M, N, Q, R, U). However, unlike Ptf1a, misexpressed Tfap2b did not induce the differentiation of $\mathrm{TH}+$ dopaminergic amacrine cells or significantly suppress the differentiation of bipolar and Müller cells (Figure 6 K, L, O, P, U; Figure 3). Thus, Tfap2b has the ability, albeit weaker than that of Ptf1a, to promote the differentiation of both glycinergic and GABAergic amacrine cells.

\section{Tfap2a facilitates amacrine cell differentiation}

As a homolog of Tfap $2 b$, Tfap $2 \mathrm{a}$ is expected to have a similar role during retinal cell development as Tfap $2 b$. Indeed, we found that Tfap2a misexpressed in retinas of newborn mice significantly increased GFP+ cells distributed within the inner half of the INL and GCL whereas it significantly reduced those in the ONL (Additional file 6: Figure S5A-D). Similar to Tfap2b, it caused obvious increase in the number of GFP+ cells immunoreactive for Pax6 and GLYT1 in transfected retinas (Additional file 6: Figure S5E-H), and smaller increase in the number of GABA+ and Gad65+ GABAergic amacrine cells (Additional file 6: Figure S5I-L), but had no effect on the formation of $\mathrm{TH}+$ dopaminergic neurons (Additional file 6: Figure S5M, N). Thus, Tfap2a may act similarly as Tfap2b to facilitate the differentiation of both glycinergic and GABAergic amacrine cells during retinogenesis.

\section{Tfap $2 a$ and $2 b$ are required for amacrine cell differentiation}

To determine whether Tfap2a and $2 \mathrm{~b}$ are necessary for amacrine cell differentiation, we sought to simultaneously knock down Tfap $2 a$ and $2 b$ expression in retinal precursors. To this end, we screened for target sequences (oligonucleotides) in these two genes that are 


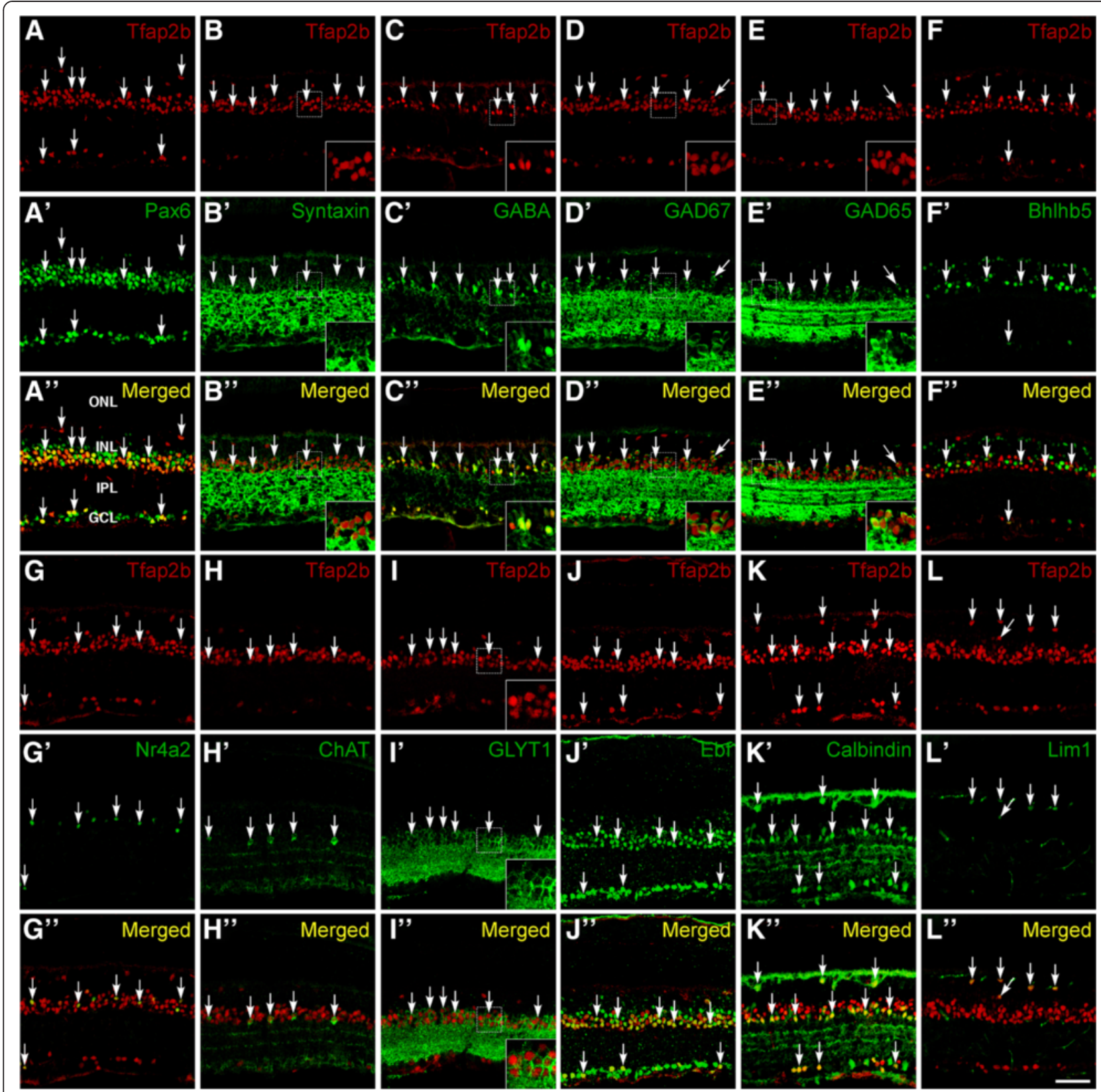

Figure 5 Expression of Tfap2b in amacrine and horizontal cells. (A-L) Sections from P21 mouse retinas were double-immunolabeled with an anti-Tfap2b antibody and those against the indicated cell type-specific markers. Tfap2b is expressed in amacrine cells co-expressing Pax6 (A), syntaxin (B), GABA (C), Gad67 (D), Gad65 (E), Bhlhb5 (F), Nr4a2 (G), ChAT (H), GLYT1 (I), Ebf (J), or calbindin (K). It is also expressed by horizontal cells co-expressing calbindin or Lim1 $(\mathbf{K}, \mathbf{L})$. However, there is no expression of Tfap2b in Bhlhb5+ bipolar cells within the outer half of the INL (F). Abbreviations: GCL, ganglion cell layer; INL, inner nuclear layer; IPL, inner plexiform layer; ONL, outer nuclear layer. Scale bar: A-L, $47.6 \mu m$.

effective in knocking down the expression of Tfap $2 a$ or Tfap $2 b$ by shRNA-mediated interference. A Tfap2a shRNA (Tfap2ai5) expressed from the RNAi vector pU6 [34] was found to dramatically reduce GFP expression in HEK293 cells co-transfected with the pCIG-Tfap2a expression plasmid (containing a Tfap2a-IRES-GFP cassette) (Additional file 7: Figure S6A-D). Similarly, we identified a Tfap2b shRNA (Tfap2bi4) that was effective and specific in knocking down Tfap $2 b$ expression in cell culture (Additional file 7: Figure S6A, E-G).

To investigate whether simultaneous knockdown of both Tfap $2 a$ and $2 b$ expression has any functional consequence, we co-electroporated Tfap $2 a$ and $2 b$ shRNAs or pU6 plasmid with the pCIG vector into P0 mouse retinas and collected them at P12 for analysis. The proportions of $\mathrm{GFP}^{+}$progeny distributed in different retinal cell 


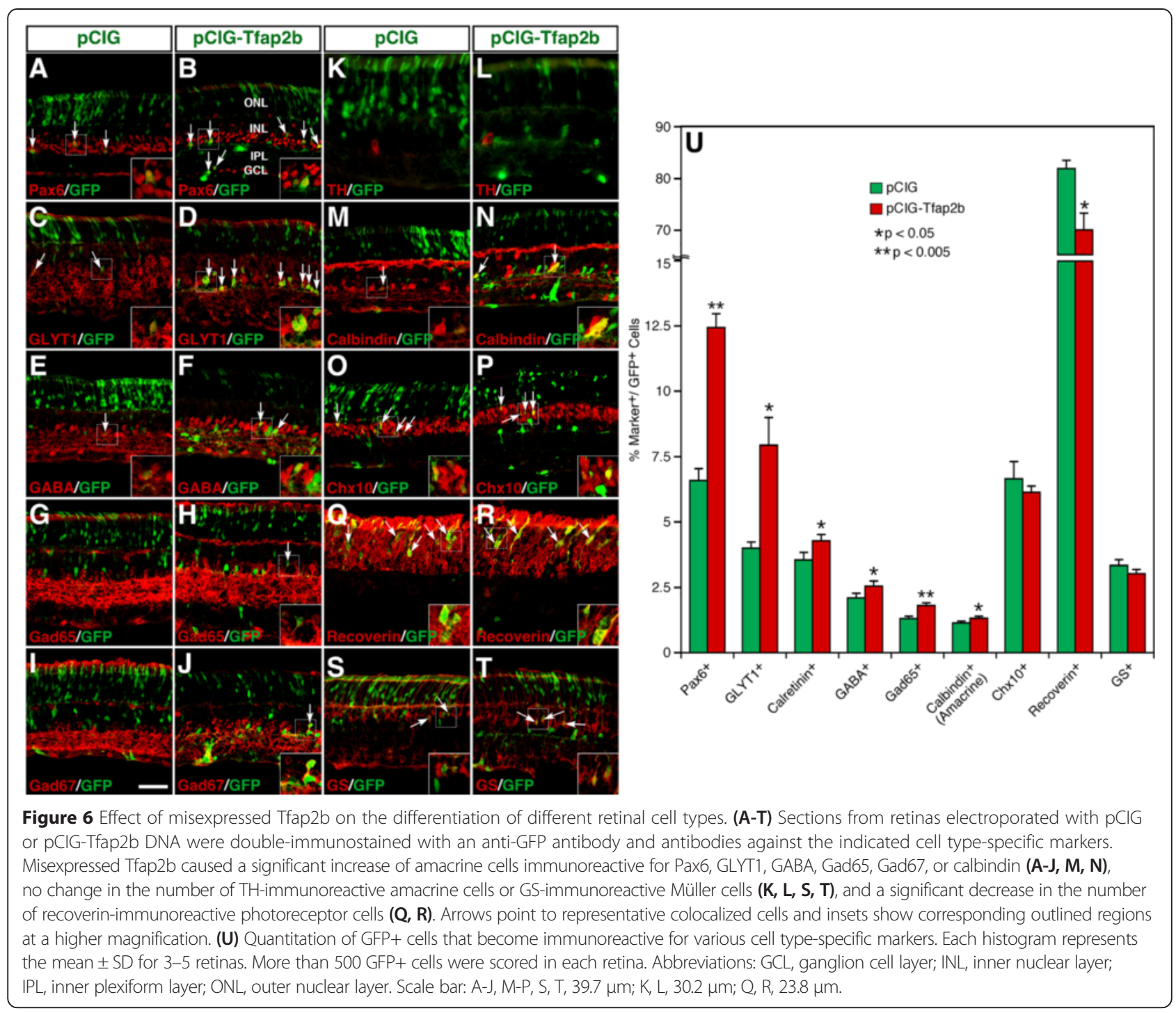

layers were quantified. In retinas transfected with both shRNAs (Tfap2ai5 + bi4), compared to the control, the proportion of $\mathrm{GFP}^{+}$cells distributed to the inner half of the INL decreased significantly from $8.9 \%$ to $3.3 \%$ (Additional file 8: Figure S7); whereas the ratio of $\mathrm{GFP}^{+}$ cells differentiated as photoreceptors in the ONL increased from $81.3 \%$ to $87.5 \%$ (Additional file 8: Figure S7). No change was seen in the proportion of $\mathrm{GFP}^{+}$cells distributed to the outer half of the INL (Additional file 8: Figure S7). The significant reduction of cells in the INL is consistent with the idea that Tfap $2 a$ and $2 b$ are redundantly required for proper differentiation of amacrine cells, which normally reside in the inner half of the INL.

Transfection of Tfap $2 a$ and $2 b$ shRNAs led to more than 3-fold decrease in the fraction of GFP+ cells immunolabeled by the antibody cross-reacting with both Tfap2a and 2b (Figure 7S-U), demonstrating the effectiveness of the double knockdown strategy. Consistent with decreased GFP+ cells in the INL, it caused a significant reduction of amacrine cells immunostained by various molecular markers including Pax6, GLYT1, calretinin, GABA, GAD65, GAD67, and calbindin (Figure 7A-L, U). For instance, in retinas transfected with both shRNAs, the proportion of Pax6+, GLYT1+, GABA + and GAD65+ cells decreased from $6.8 \%, 4.2 \%$, $2.0 \%$ and $1.2 \%$ to $2.1 \%, 0.9 \%, 0.6 \%$ and $0.2 \%$, respectively (Figure $7 \mathrm{U}$ ). By contrast, misexpression of Tfap $2 a$ and $2 b$ shRNAs increased the percentage of recoverin + photoreceptors from $81.9 \%$ to $87.1 \%$ and had no effect on the differentiation of Ch10+ bipolar cells and GS+ Müller cells (Figure $7 \mathrm{M}-\mathrm{R}, \mathrm{U}$ ). These results thus indicate that Tfap $2 \mathrm{a}$ and $2 \mathrm{~b}$ factors are not only sufficient but also necessary for promoting the differentiation of glycinergic and GABAergic amacrine cells during retinal development. 


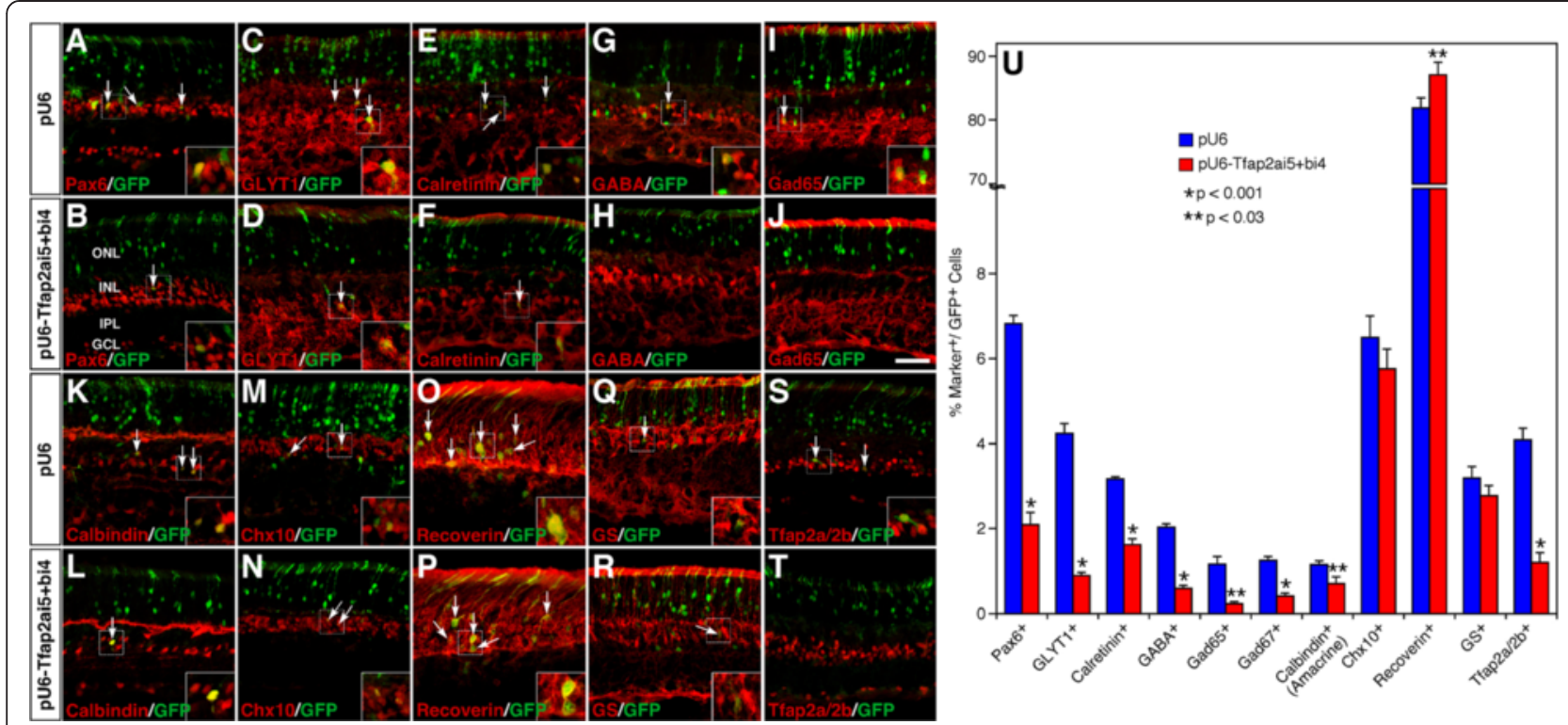

Figure 7 Effect of knocking down Tfap2a and $2 b$ expression on the formation of different retinal cell types. (A-T) Sections from retinas co-electroporated with pCIG and RNAi vectors pU6 or pU6-Tfap2ai5 and pU6-Tfap2bi4 were double-immunostained with an anti-GFP antibody and antibodies against the indicated cell type-specific markers. Simultaneous knockdown of both Tfap2a and $2 b$ expression led to a dramatic reduction of Tfap2a- and Tfap2b-immunoreactive cells (S, T), a significant decrease of amacrine cells immunoreactive for Pax6, GLYT1, calretinin, GABA, Gad65, and calbindin (A-L), no change in the number of Chx10-immunoreactive bipolar cells and GS-immunoreactive Müller cells (M, N, $\mathbf{Q}$, R), but a significant increase of recoverin-immunoreactive photoreceptor cells $\mathbf{(} \mathbf{O}, \mathbf{P})$. Arrows point to representative colocalized cells and insets show corresponding outlined regions at a higher magnification. (U) Quantitation of GPF+ cells that are immunoreactive for various cell type-specific markers. Each histogram represents the mean \pm SD for 3 retinas. More than 600 GFP+ cells were scored in each retina. Abbreviations: GCL, ganglion cell layer; INL, inner nuclear layer; IPL, inner plexiform layer; ONL, outer nuclear layer. Scale bar: A-N, Q-T, 39.7 $\mu$ m; O, P, $23.8 \mu \mathrm{m}$.

\section{Discussion}

Ptf1a acts as a general regulator to specify different amacrine and horizontal cell subtypes

Ptf1a is required to specify GABAergic versus glutamatergic neurons in the mouse spinal cord and cerebellum $[35,36]$. In the Xenopus retina, it also preferentially promotes the formation of GABAergic amacrine and horizontal cells [19]. However, in the mouse retina, Ptf1a appears to be necessary for specifying all amacrine and horizontal cell types $[15,16]$. In the chick retina, its overexpression promotes all horizontal cell subtypes including GABAergic $\mathrm{H} 1 / \mathrm{H} 2$ cells as well as non-GABAergic H3 cells [18]. Similarly, in the zebrafish retina, Ptf1a is expressed by all subtypes of amacrine cells and appears to be necessary and sufficient for their specification [20,37]. In this work, we show that in the mouse retina, Ptf1a has the ability to promote the fates of not only GABAergic but also glycinergic amacrine cells, and in fact, it has a much more potent activity to promote glycinergic than GABAergic amacrine neuron differentiation (Figure 3). Therefore, our data lend support to the idea that Ptf1a may act as a general transcriptional regulator to specify all subtypes of amacrine and horizontal cells during retinal development, although its function may exhibit some species specificity.
Tfap2a and $2 b$ function downstream of Ptf1a for amacrine and horizontal cell differentiation

Given the essential role for Ptfla in specifying subsets of neurons in the CNS, efforts have been undertaken to identify its downstream targets during neural development [38-40]. For instance, Neurog2 has been found to act as a direct Ptfla target in the specification of GABAergic neurons in the dorsal spinal cord and cerebellum, and Nephrin and Neph3 expression is directly regulated by Ptf1a in developing neurons $[39,40]$. However, the downstream genes of Ptfla involved in retinal development are yet to be identified. In this study, we profiled transcriptomes of wild type and Ptf1a mutant retinas by RNA-seq and identified Tfap $2 a$ and $2 b$ as two transcription factor genes prominently downregulated in the mutant retina. Interestingly, our previous microarray profiling analysis has identified the same two genes as those significantly downregulated in Foxn4 mutant retinas [29]. Given the known epistatic relationship between Foxn4 and Ptf1a during retinal development $[15,17]$, however, Tfap $2 a$ and $2 b$ are unlikely to be direct targets of Foxn4.

Previous studies have shown that both Tfap $2 \mathrm{a}$ and $2 \mathrm{~b}$ are essential for embryonic development and involved in eye morphogenesis. Targeted deletion of either gene in mice causes perinatal lethality [41-43]. Tfap $2 a$ inactivation 
results in anencephaly, craniofacial cleft, thoracoabdominoschisis, and lens defect [42-44]. Similarly, mutations in human TFAP2A are associated with the Branchio-Oculo-Facial Syndrome with variable ocular anomalies including microphthalmia or anophthalmia, iris and chorioretinal coloboma, strabismus, and cataract $[24,25,45,46]$. During mouse retinogenesis, Tfap2a and $2 \mathrm{~b}$ are overlappingly expressed in postmitotic amacrine and horizontal cells [26-28]. Conditional inactivation of Tfap $2 a$ fails to cause any retinal defect [26]. However, when the conditional Tfap $2 a$ line was bred with the Tfap $2 b$ conventional knockout strain to obtain double knockout embryos, there was a complete loss of horizontal cells, indicating that Tfap $2 \mathrm{a}$ and $2 \mathrm{~b}$ are redundantly required for horizontal cell differentiation [28], consistent with the expected role for them as Ptf1a downstream effectors. On the other hand, there was no obvious change in the number of amacrine cells in the double mutant retina except for a minor migratory defect [28], begging the question whether Tfap2a and $2 \mathrm{~b}$ can mediate the function of Ptf1a in amacrine cell differentiation.

We utilized both overexpression and knockdown approaches to assess the role of Tfap2a and $2 b$ in amacrine cell development. Previous studies have shown that many of the transcription factors involved in retinal development act as both positive and negative regulators depending on the cell types. For example, Barhl2 promotes glycinergic amacrine cell differentiation while negatively regulating the formation of bipolar and Müller cells [33]. Rax1 and Hes1 are able to promote the Müller glial cell fate as well as inhibit neuronal cell differentiation [47]. Similarly, we are able to show that misexpressed Tfap2a and $2 \mathrm{~b}$ can function as positive factors to promote differentiation of glycinergic and GABAergic amacrine cells while negatively regulating the formation of photoreceptors. Therefore, Tfap2a and $2 \mathrm{~b}$ indeed can fulfill their expected role in mediating the function of Ptf1a in amacrine cell differentiation. However, it appears that they have a much weaker activity than Ptfla in facilitating and suppressing retinal cell types: 1) the number of glycinergic amacrine neurons induced by misexpressed Tfap2b is about 3 -fold less than those induced by Ptfla (compare Figures 3,6 ); 2) neither Tfap2a nor $2 b$ is able to promote the formation of $\mathrm{TH}+$ dopaminergic amacrine cells while Ptfla has a potent activity to do so; and 3) Tfap2b is unable to inhibit bipolar and Müller cell differentiation while Ptf1a is. Thus, Tfap2a and $2 b$ are able to mediate only part of the Ptf1a function in amacrine cell development and there should be other downstream factors that participate as Ptfla effectors.

To investigate the necessity for Tfap2a and $2 \mathrm{~b}$ in amacrine cell differentiation, we simultaneously knocked down Tfap $2 a$ and $2 b$ expression by RNAi in newborn retinal precursors to circumvent the issue of functional redundancy. This genetic manipulation resulted in a significant reduction of glycinergic and GABAergic amacrine cells accompanied with a concomitant increase of photoreceptors. This result tallies well with the gain-offunction data to demonstrate that Tfap $2 \mathrm{a}$ and $2 \mathrm{~b}$ are both necessary and sufficient to promote amacrine cell differentiation, but differs from that of the reported Tfap $2 a$ and $2 b$ double mutant retina where no obvious amacrine cell loss was seen [28]. This discrepancy may result from the fact that further analysis of amacrine cell differentiation was impossible beyond the neonatal stage due to perinatal lethality of the double mutant embryo on the conventional Tfap $2 b$ knockout background [28]. It would be necessary to achieve retina-specific inactivation of both Tfap $2 a$ and $2 b$ to circumvent the lethal phenotype and resolve the discrepancy.

\section{Transcriptional regulatory pathways to amacrine and horizontal cell development}

Despite the requirement of Pax6 for retinal progenitors to acquire multipotency, the absence of Pax6 in mice permits the formation of amacrine cells [48], implicating that other factors are sufficient to make the progenitors competent for the generation of amacrine cells. The identity of these additional regulators have been gradually revealed over time. Targeted inactivation of Foxn4, RORß1 or Ptf1a in mice result in a similar retinal phenotype, i.e. elimination of horizontal cells and loss of the great majority of amacrine cells, whereas their misexpression in newborn retinas leads to increased amacrine cells (Figure 3) [13,15,16,21]. The absence of either Foxn 4 or ROR $\beta 1$ causes marked downregulation of Ptf1a expression but Foxn4 expression remains unchanged in the Ptf1a mutant retina $[15,21,29]$. Our RNA-seq data also reveal no significant change in the expression level of Rorb in the Ptfla mutant. Given the normal expression of Foxn4 in the ROR $\beta 1$ null retina [21], Foxn4 and ROR $\beta 1$ are likely to act in parallel upstream of Ptf1a (Figure 8), and indeed are shown to directly and synergistically activate Ptf1a expression through binding to enhancer elements [21].

Through combined bioinformatic and genetic analyses, we are able to show that Tfap $2 a$ and $2 b$ are dramatically downregulated in the Ptf1a null retina, and their knockdown causes decreased amacrine cell differentiation whereas their overexpression leads to the opposite outcome. Given that knockout of both Tfap $2 a$ and $2 b$ results in essentially complete loss of horizontal cells [28], we propose a Foxn4/ROR 31 -Ptf1a-Tfap2a/2b transcriptional regulatory cascade that underlies the competence, specification and differentiation of amacrine and horizontal cells during retinal development (Figure 8). Onecut 1 and Onecut 2 have been shown to be required for 


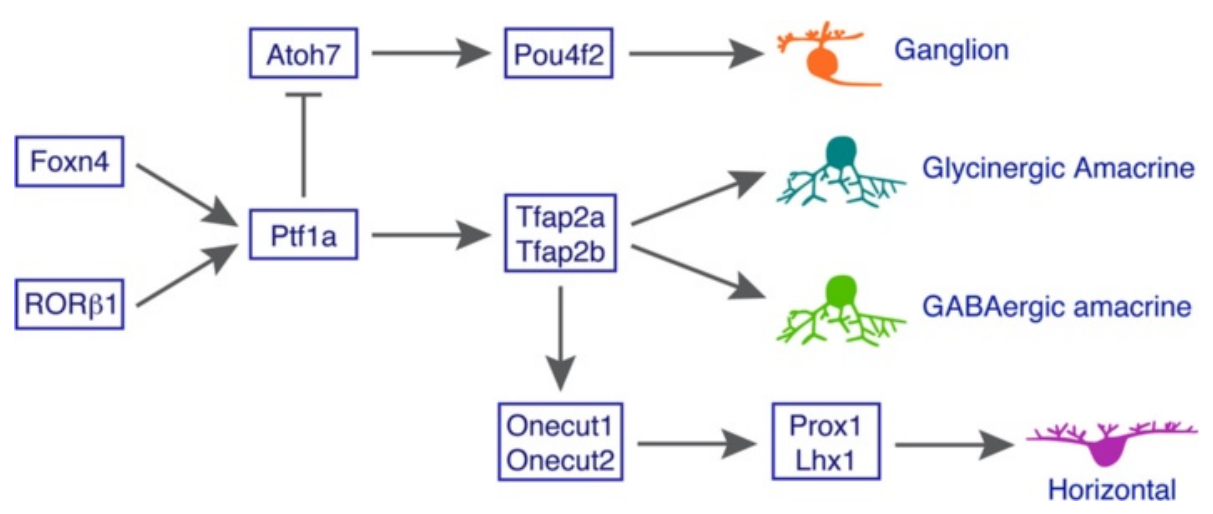

Figure 8 Model by which Tfap2 and Ptf1a factors promote the differentiation of amacrine and horizontal cells. Tfap2a and 2b act downstream of Ptf1a to promote the differentiation of glycinergic and GABAergic amacrine cells while functioning upstream of Onecut1 and 2 for the specification of horizontal cells. Ptf1a, whose expression is activated by both Foxn4 and ROR 1, is required not only for specifying amacrine and horizontal cells in part by activating Tfap2 $a$ and $2 b$ expression, but also for suppressing the ganglion cell fate by repressing Atoh7 expression.

horizontal cell differentiation by activating the expression of Prox 1 and $L h x 1$, two transcription factor genes also involved in horizontal cell development [49-52]. However, they appear not to be required for activating Tfap $2 a$ and $2 b$ expression because RNA-seq reveals that there is no change of Tfap $2 a$ expression and even significant upregulation of $2 b$ expression in Onecut 1 and 2 double mutant retinas [52]. Since Onecut1 and 2 expression is downregulated in Tfap $2 a$ and $2 b$ double mutant retinas (Judith West-Mays, personal communication), these two Tfap2 factors are likely to function upstream of the Onecut factors to control horizontal cell differentiation (Figure 8). We and others have also shown that Ptfla inactivation causes overproduction of retinal ganglion cells while its misexpression inhibits ganglion cell differentiation and expression of Atoh7 (Figure 4) $[15,16,18]$, a transcription factor essential for conferring the ganglion cell competence [53-55]. Thus, Ptf1a appears to ensure proper specification of competent precursors to amacrine and horizontal cells not only by promoting these two cell fates but also by suppressing the alternative ganglion cell fate (Figure 8).

\section{Methods}

\section{Mice}

All procedures in animals were performed according to the IACUC standards, and approved by Rutgers, the State University of New Jersey, and/or by Zhongshan Ophthalmic Center and Sun Yat-Sen University. All mice were maintained and bred in the university vivarium with normal diet. The C57BL6/J mice were obtained from the Jackson Laboratory (Bar Harbor, ME). The CD1 mice were purchased from the Charles River Laboratories (Wilmington, MA). The Foxn4 and Ptfla knockout mouse lines were reported previously $[13,56]$ and maintained by breeding with C57BL6/J mice. The starting stage of mouse embryos was defined as E0.5 when the copulation plug was seen in the morning. Mouse genotype was determined by standard PCR.

\section{RNA-Seq}

Total RNA was extracted from E14.5 wild type and Ptf1a null mutant retinas using the TRIzol reagent (Invitrogen) according to the manufacturer's instruction. Ribosomal RNA was depleted prior to RNA-seq library preparation. The prepared DNA was sequenced using an Illumina HiSeq 2000 sequencer. The obtained sequence reads were trimmed and mapped to the mouse reference genome (mm10) using Tophat [57] (http://ccb.jhu.edu/software/ tophat/index.shtml). Gene expression and changes were analyzed using Cufflinks (http://cole-trapnell-lab.github.io/ cufflinks/), whose output was then further analyzed by CummeRbund (http://compbio.mit.edu/cummeRbund/) and iReport (Qiagen). Cluster analysis was performed using Genesis [58] and GO term enrichment using DAVID [59] (http://david.abcc.ncifcrf.gov/).

\section{Antibodies and immunostaining}

Tissue processing and immunostaining were carried out as described previously [13,32]. The following primary antibodies were used: mouse anti-Brn3a (1:100, Cat: MAB1585, Millipore); goat anti-Brn3b (1:200, Cat:sc-6026, Santa Cruz Biotech.); goat anti-Bhlhb5/BETA3 (1:800, Cat: sc-6045, Santa Cruz Biotech.); rabbit anti-calbindin D-28 k (1:3000, Cat: CB-38, Swant); mouse anti-calretinin (1:1000, Cat: mab1568, Millipore); goat anti-choline acetyltransferase (ChAT) (1:300, Cat: AB144P, Millipore); sheep anti-Chx10 (1:1600, Cat: x1180p, Exalpha); rabbit anti-Dab1 (1:200, Cat: sc-13981, Santa Cruz Biotech.); goat anti-EBF (1:40, Cat:sc-15888, Santa Cruz Biotech.); rabbit anti-GABA (1:3000, Cat: a2052, Sigma); mouse anti-Gad65 (1:5000, Cat: 559931, BD Biosciences); mouse anti-Gad67 (1:1000, 
Cat: mab5406, Millipore); rabbit anti-GFP (1:800, Cat: 598, MBL International); Goat anti-GFP (1:1500, Cat: ab6673, Abcam); mouse anti-glutamine synthetase (1:5000, Cat: mab302, Millipore); goat anti-GLYT1 (1:4000, Cat: AB1770, Millipore); mouse anti-Lim1/2 [1:100, Cat: 4 F2, Developmental Studies Hybridoma Bank (DSHB)]; rabbit antiNr4a2/Nurr1 (1:1000, Cat: sc-990, Santa Cruz Biotech.); rabbit anti-Pax6 (1:2000, Cat: ab5409, Millipore); rabbit anti-recoverin (1:10000, Cat: ab5585, Millipore); Mouse anti-syntaxin (1:3000, Cat: S0664, Sigma); rabbit anti-Sox9 (1:1000, Cat: ab5535, Millipore); rabbit anti-Tfap2a/2b (1:500, Cat: sc-184, Santa Cruz Biotech.); rabbit anti-Tfap2b (1:100, Cat: sc-8976, Santa Cruz Biotech.); mouse antiTfap2a (1:200, Cat: 5E4, DSHB); and rabbit anti-tyrosine hydroxylase (1:2000, Cat: ab152, Millipore). Secondary antibodies conjugated with fluorophore Alexa 488 or 594 were purchased from Life Technologies. Images were captured by a Leica TCS-SP2 confocal system or with a Nikon Eclipse 80i microscope.

\section{Plasmid electroporation and virus infection}

The pCIG vector was reported previously [30-32]. It is a mammalian expression vector containing the CMV enhancer, chicken $\beta$-actin promoter, multiple cloning sites (MCS), IRES-eGFP and rabbit $\beta$-globin PolyA sequences. For misexpression experiments, the full-length ORFs of mouse Ptf1a, Tfap2a and Tfap2b were amplified from retinal cDNA and subcloned into the MCS of the PCIG vector. $0.5-2 \mu \mathrm{g}$ of each plasmid was injected into the subretinal space at P0 and electroporated into retinal cells [60]. Injected retinas were collected at P12 for analysis.

The methods to prepare retroviruses, infect retinas and collect samples are described in detail previously $[32,60]$. For retrovirus preparation, the full-length ORF of mouse Ptf1a was cloned into the MMLV-based replication-incomplete retroviral vector pLZRSA-IRESGFP [33]. E13.5 retinal explants were infected with retroviruses and harvested after 4.5 days in culture to analyze horizontal and ganglion cells or collected after 12.5 days in culture for analysis of other cell types.

\section{shRNA plasmids and RNAi interference}

For RNAi knockdown experiments, selected small hairpin sequences were inserted into the shRNA interference vector pBS/U6 containing the human U6 promoter [34]. Knockdown efficiency was tested by cotransfection into 293 cells of the shRNA plasmid, pmCherry-N1 vector and pCIG construct containing the corresponding gene. To rule out differences in transfection efficiency, pmCherry-N1 was used as a red fluorescence marker to monitor transfection efficiency. The constructs with the best knockdown efficiency were used in the retinal knockdown experiments. The targeting sequence used for Tfap2a is: 5'-AACATTCCGATCCCAATGAGC-3'
(Tfap2ai5), and for Tfap2b is: 5'-CTACTCAGTTC AACTTCAAAGTACA-3' (Tfap2bi4). To perform retinal knockdown, $\mathrm{pBS} / \mathrm{U} 6$ constructs and $\mathrm{pCIG}$ vector (as a GFP reporter) were mixed at a ratio of $2: 1(\mu \mathrm{g} / \mu \mathrm{l})$ and $1 \mu \mathrm{l}$ of the mixture was injected into the subretinal space of P0 CD1 mice. Electroporation was carried out immediately following injection [32]. Transfected retinas were collected at P12 when the great majority of retinal cells are determined and developed into mature cell types.

\section{Semi-quantitative RT-PCR}

Total RNA was isolated from E14.5 wild type and Ptf1a mutant mouse retinas, and cDNA was made using the NEB Reverse Transcription Kit. The following primers were used for semi-quantitative RT-PCR (all from 5 ' to 3'): Tfap $2 a$, GCCTGAATCCTCTGCACGC and GTCC TCGTGCCGCCGATA; Tfap $2 b$, CCAGCTCTCCGGCC TTGATC and CAACTGACTGCACGTCTTCCATG; Gapdh, CGTGCCGCCTGGAGAAACCTG and GAGT GGGAGTTGCTGTTGAAGTCGC. The products were amplified for 27 cycles and visualized on a 1.5\% agarose gel.

\section{Quantification and statistical analysis}

For misexpression experiments, depending on the frequency or ratio of each cell type, hundreds to thousands of GFP+ cells in each infected retina were scored; at least 3 retinas were used for each individual cell marker. All quantification data were subjected to significance test using two sample Student's t-test with unequal variances and two tails.

\section{Additional files}

Additional file 1: Table S1. List of genes differentially expressed between E14.5 wild type and Ptf1a mutant retinas.

Additional file 2: Figure S1. Expression of Tfap2b during mouse retinal development. (A-D) Retinal sections from the indicated developmental stages were immunostained with an anti-Tfap $2 \mathrm{~b}$ antibody and weakly counterstained with DAPI. Tfap2b-immunoreactive cells are seen in scattered cells at E13.5 in the central retina, and gradually become concentrated in the presumptive inner nuclear layer from E14.5 to E16.5 (B-D). (E-G) A P21 retinal section was double-immunolabeled with anti-Tfap2a and anti-Tfap2b antibodies. Tfap2a and 2b are colocalized in the great majority of immunoreactive cells. Arrows point to labeled horizontal cells. Abbreviations: GCL, ganglion cell layer; $\mathrm{INL}$, inner nuclear layer; IPL, inner plexiform layer; L, lens; ONBL, outer neuroblastic layer; $\mathrm{ONL}$, outer nuclear layer; $\mathrm{OPL}$, outer plexiform layer; $\mathrm{R}$, retina. Scale bar in C: A, B, $50 \mu \mathrm{m} ; \mathrm{C}, \mathrm{D}, 25 \mu \mathrm{m}$. Scale bar in G: E-G, $47.6 \mu \mathrm{m}$.

Additional file 3: Figure S2. Ptf1a misexpression alters the distribution pattern and morphology of retinal cells. (A) Schematics of the PCIG and pCIG-Ptf1a expression plasmids. The internal ribosomal entry site (IRES) allows for efficient expression of both Ptfla and GFP. (B, C) Transfected GFP + cells were visualized in retinal sections that were weakly counterstained with TOPRO3. Ptf1a misexpression causes an obvious increase of GFP+ cells located in the INL but a reduction of photoreceptors residing in the ONL. (D) Percentages of GFP+ cells located in different cellular layers of the retina (means \pm SD). Three retinas were scored for each virus and more than 700 $\mathrm{GFP}^{+}$cells were counted in each retina. Abbreviations: GCL, ganglion cell 
layer; INL, inner nuclear layer; IPL, inner plexiform layer; ONL, outer nuclear layer; and OPL, outer plexiform layer. Scale bar: B, C, $39.7 \mu \mathrm{m}$.

Additional file 4: Figure S3. Expression of Tfap2b in retinal cell types. (A-G) Sections from P21 mouse retinas were double-immunolabeled with an anti-Tfap2b antibody and those against the indicated cell type-specific protein markers. Tfap $2 \mathrm{~b}$ is colocalized with calretinin and TH in amacrine cells, but not expressed in Brn3a- or Brn3b-immunoreactive ganglion cells, Chx10-immunoreactive bipolar cells, Sox9-immunoreactive Müller cells, or in recoverin-immunoreactive photoreceptors. $(\mathbf{H})$ Percentages of marker-positive retinal cells that are immunoreactive for Tfap2b. Abbreviations: GCL, ganglion cell layer; INL, inner nuclear layer; IPL, inner plexiform layer; ONL, outer nuclear layer. Scale bar: A-G, $47.6 \mu \mathrm{m}$.

Additional file 5: Figure S4. Tfap2b misexpression alters the distribution pattern and morphology of retinal cells. (A) Schematics of the pCIG and pCIG-Tfap2b expression plasmids. (B, C) Transfected GFP+ cells were visualized in retinal sections that were weakly counterstained with TOPRO3. Tfap2b misexpression causes an increase of GFP+ cells located in the INL but a decrease of photoreceptors residing in the ONL. (D) Percentages of GFP+ cells located in different cellular layers of the retina (means $\pm \mathrm{SD}$ ). Three retinas were scored for each virus and more than $700 \mathrm{GFP}^{+}$cells were counted in each retina. Abbreviations: GCL, ganglion cell layer; INL, inner nuclear layer; IPL, inner plexiform layer; ONL, outer nuclear layer; and OPL, outer plexiform layer. Scale bar: B, C, $39.7 \mu \mathrm{m}$.

Additional file 6: Figure S5. Effect of misexpressed Tfap2a on the differentiation of different retinal cell types. (A) Schematics of the PCIG and pCIG-Tfap2a expression plasmids. (B, C) Transfected GFP+ cells were visualized in retinal sections that were weakly counterstained with DAPI. Tfap2a misexpression results in an increase of GFP+ cells located in the INL but a decrease of photoreceptors residing in the ONL. (D) Percentages of GFP+ cells located in different cellular layers of the retina (means \pm SD). Three retinas were scored for each virus and more than $1000 \mathrm{GFP}^{+}$cells were counted in each retina. (E-N) Sections from retinas electroporated with PCIG or pCIG-Tfap2a DNA were double-immunostained with an anti-GFP antibody and antibodies against the indicated cell type-specific markers. Misexpressed Tfap2a increased amacrine cells immunoreactive for Pax6, GLYT1, GABA, or Gad65 (E-L), but not the number of TH-immunoreactive dopaminergic neurons $(\mathrm{M}, \mathrm{N})$. Arrows point to representative colocalized cells and insets show corresponding outlined regions at a higher magnification. Abbreviations: $\mathrm{GCL}$, ganglion cell layer; INL, inner nuclear layer; IPL, inner plexiform layer; ONL, outer nuclear layer; and OPL, outer plexiform layer. Scale bar: B, C, E-L, $39.7 \mu \mathrm{m}$; $\mathrm{M}, \mathrm{N}, 30.2 \mu \mathrm{m}$.

Additional file 7: Figure S6. Specificity of the Tfap $2 a$ and $2 b$ shRNA. (A) Schematics of Tfap $2 a$ and $2 b$ protein structural domains and regions targeted by the corresponding shRNA. AD, activation domain; $\mathrm{HSH}$, helix-span-helix motif. (B-G) In transfected HEK293 cells, the Tfap2ai5 shRNA greatly reduced expression of the Tfap2a-IRES-GFP cassette, as marked by GFP; whereas it had no effect on the expression of Tfap2b (B,C,E,F). The opposite was true for the Tfap2bi4 shRNA (B,D,E,G). Comparable transfection efficiency was observed by the presence of similar number of mCherry-expressing cells co-transfected with the pmCherry-N1 expression plasmid ( $\left.B^{\prime}-G^{\prime}\right)$

Additional file 8: Figure S7. Reducing Tfap $2 a$ and $2 b$ expression alters the distribution pattern of retinal cells. (A, B) Simultaneous transfection of Tfap $2 a$ and $2 b$ shRNA caused a significant decrease of GFP+ cells distributed in the INL. (C) Percentages of GFP+ cells located in different cellular layers of retinas transfected with pU6 or with both pU6-Tfap2ai5 and pU6-Tfap2bi4 plasmids (mean $\pm \mathrm{SD}$ ). Three retinas were scored for each plasmid and more than $900 \mathrm{GFP}^{+}$cells were counted in each retina. Abbreviations: GCL, ganglion cell layer; INL, inner nuclear layer; IPL, inner plexiform layer; ONL, outer nuclear layer; and OPL, outer plexiform layer. Scale bar: A, B, $39.7 \mu \mathrm{m}$.

\section{Abbreviations}

ChAT: Choline acetyltransferase; GABA: $\gamma$-aminobutyric acid; GAD: Glutamic acid decarboxylase; GFP: Green fluorescent protein; GLYT1: Glycine transporter 1; GO: Gene ontology; GS: Glutamine synthetase; INL: Inner nuclear layer; IRES: Internal ribosome entry site; MMLV: Moloney murine leukemia virus; ONL: Outer nuclear layer; ORF: Open reading frame; shRNA: Short hairpin ribonucleic acid; TH: Tyrosine hydroxylase.

\section{Competing interests}

The authors declare that they have no competing interests.

\section{Authors' contributions}

$K J, H J, D X, M Z, J Z$ and $M X$ designed and performed the experiments, and analyzed the data. KJ, HJ and MX wrote the manuscript. All authors read and approved the final manuscript.

\section{Acknowledgements}

We thank Dr. Shenguo Li for thoughtful comments on the manuscript and are grateful to Dr. Christopher Wright for generously sharing the Ptfla knockout mouse line. This work was supported in part by the Fundamental Research Funds of the State Key Laboratory of Ophthalmology, Sun Yat-sen University (to M.X.) the National Basic Research Program (973 Program) of China (2015CB964600 to M.X.), and the National Institutes of Health (EY020849 and EY012020 to M.X.).

\section{Author details}

'State Key Laboratory of Ophthalmology, Zhongshan Ophthalmic Center, Sun Yat-sen University, 54 South Xianlie Road, Guangzhou 510060, China. ${ }^{2}$ Center for Advanced Biotechnology and Medicine and Department of Pediatrics, Rutgers University-Robert Wood Johnson Medical School, 679 Hoes Lane West, Piscataway, NJ 08854, USA. ${ }^{3}$ Systems Biology Center, National Heart, Lung and Blood Institute, National Institutes of Health, Bethesda, MD 20892, USA. ${ }^{4}$ Present address: Institute for Cell Engineering, Departments of Neurology and Neuroscience, Johns Hopkins University School of Medicine, 733 North Broadway, Baltimore, MD 21206, USA.

\section{Received: 25 January 2015 Accepted: 17 April 2015}

\section{Published online: 13 May 2015}

\section{References}

1. Livesey FJ, Cepko CL. Vertebrate neural cell-fate determination: lessons from the retina. Nat Rev Neurosci. 2001;2:109-18.

2. Harris WA. Cellular diversification in the vertebrate retina. Curr Opin Genet Dev. 1997;7:651-8.

3. Yang XJ. Roles of cell-extrinsic growth factors in vertebrate eye pattern formation and retinogenesis. Semin Cell Dev Biol. 2004;15:91-103.

4. Xiang M. Intrinsic control of mammalian retinogenesis. Cell Mol Life Sci. 2013;70:2519-32.

5. Masland RH. The fundamental plan of the retina. Nat Neurosci. 2001;4:877-86.

6. Masland RH. Neuronal diversity in the retina. Curr Opin Neurobiol. 2001;11:431-6.

7. MacNeil MA, Heussy JK, Dacheux RF, Raviola E, Masland RH. The shapes and numbers of amacrine cells: matching of photofilled with Golgi-stained cells in the rabbit retina and comparison with other mammalian species. J Comp Neurol. 1999:413:305-26.

8. MacNeil MA, Masland RH. Extreme diversity among amacrine cells: implications for function. Neuron. 1998;20:971-82.

9. Menger N, Pow DV, Wassle $\mathrm{H}$. Glycinergic amacrine cells of the rat retina. J Comp Neurol. 1998:401:34-46.

10. Pourcho RG, Goebel DJ. A combined Golgi and autoradiographic study of $\left({ }^{3} \mathrm{H}\right)$ glycine-accumulating amacrine cells in the cat retina. J Comp Neurol. 1985:233:473-80.

11. Vaney DI. The mosaic of amacrine cells in the mammalian retina. Prog Retinal Res. 1990;9:49-100.

12. Pourcho RG, Goebel DJ. Neuronal subpopulations in cat retina which accumulate the GABA agonist, $\left({ }^{3} \mathrm{H}\right)$ muscimol: a combined Golgi and autoradiographic study. J Comp Neurol. 1983;219:25-35.

13. Li S, Mo Z, Yang X, Price SM, Shen MM, Xiang M. Foxn4 controls the genesis of amacrine and horizontal cells by retinal progenitors. Neuron. 2004;43:795-807.

14. Boije H, Shirazi Fard S, Ring H, Hallbook F. Forkheadbox N4 (FoxN4) triggers context-dependent differentiation in the developing chick retina and neural tube. Differentiation. 2013;85:11-9.

15. Fujitani Y, Fujitani S, Luo H, Qiu F, Burlison J, Long Q, et al. Ptf1a determines horizontal and amacrine cell fates during mouse retinal development. Development. 2006;133:4439-50.

16. Nakhai H, Sel S, Favor J, Mendoza-Torres L, Paulsen F, Duncker Gl, et al. Ptfla is essential for the differentiation of GABAergic and glycinergic amacrine cells and horizontal cells in the mouse retina. Development. 2007;134:1151-60.

17. Xiang M, Li S. Foxn4: a multi-faceted transcriptional regulator of cell fates in vertebrate development. Sci China Life Sci. 2013;56:985-93. 
18. Lelievre EC, Lek M, Boije H, Houille-Vernes L, Brajeul V, Slembrouck A, et al. Ptfla/Rbpj complex inhibits ganglion cell fate and drives the specification of all horizontal cell subtypes in the chick retina. Dev Biol. 2011;358:296-308.

19. Dullin JP, Locker M, Robach M, Henningfeld KA, Parain K, Afelik S, et al. Ptfla triggers GABAergic neuronal cell fates in the retina. BMC Dev Biol. 2007;7:110.

20. Jusuf PR, Almeida AD, Randlett O, Joubin K, Poggi L, Harris WA. Origin and determination of inhibitory cell lineages in the vertebrate retina. J Neurosci. 2011;31:2549-62

21. Liu H, Kim SY, Fu Y, Wu X, Ng L, Swaroop A, et al. An isoform of retinoidrelated orphan receptor $\beta$ directs differentiation of retinal amacrine and horizontal interneurons. Nat Commun. 2013;4:1813.

22. Eckert $D$, Buhl $S$, Weber $S$, Jager $R$, Schorle $H$. The AP-2 family of transcription factors. Genome Biol. 2005;6:246.

23. Hilger-Eversheim K, Moser M, Schorle H, Buettner R. Regulatory roles of AP-2 transcription factors in vertebrate development, apoptosis and cell-cycle control. Gene. 2000;260:1-12.

24. Milunsky JM, Maher TA, Zhao G, Roberts AE, Stalker HJ, Zori RT, et al. TFAP2A mutations result in branchio-oculo-facial syndrome. Am J Hum Genet. 2008;82:1171-7.

25. Milunsky JM, Maher TM, Zhao G, Wang Z, Mulliken JB, Chitayat D, et al. Genotype-phenotype analysis of the branchio-oculo-facial syndrome. Am J Med Genet A. 2011;155A:22-32.

26. Bassett EA, Pontoriero GF, Feng W, Marquardt T, Fini ME, Williams T, et al Conditional deletion of activating protein $2 a(A P-2 a)$ in the developing retina demonstrates non-cell-autonomous roles for AP-2a in optic cup development. Mol Cell Biol. 2007;27:7497-510.

27. Bassett EA, Williams T, Zacharias AL, Gage PJ, Fuhrmann S, West-Mays JA AP-2a knockout mice exhibit optic cup patterning defects and failure of optic stalk morphogenesis. Hum Mol Genet. 2010;19:1791-804.

28. Bassett EA, Korol A, Deschamps PA, Buettner R, Wallace VA, Williams T, et al. Overlapping expression patterns and redundant roles for AP-2 transcription factors in the developing mammalian retina. Dev Dyn. 2012;241:814-29.

29. Luo H, Jin K, Xie Z, Qiu F, Li S, Zou M, et al. Forkhead box N4 (Foxn4) activates Dll4-Notch signaling to suppress photoreceptor cell fates of early retinal progenitors. Proc Natl Acad Sci U S A. 2012;109:E553-62.

30. Megason SG, McMahon AP. A mitogen gradient of dorsal midline Wnts organizes growth in the CNS. Development. 2002;129:2087-98.

31. Misra K, Luo H, Li S, Matise M, Xiang M. Asymmetric activation of Dll4-Notch signaling by Foxn4 and proneural factors activates BMP/TGF $\beta$ signaling to specify V2b interneurons in the spinal cord. Development. 2014;141:187-98.

32. Jin $\mathrm{K}$, Jiang $\mathrm{H}, \mathrm{Mo} Z$, Xiang M. Early B-cell factors are required for specifying multiple retinal cell types and subtypes from postmitotic precursors. J Neurosci. 2010;30:11902-16.

33. Mo Z, Li S, Yang X, Xiang M. Role of the Barh/2 homeobox gene in the specification of glycinergic amacrine cells. Development. 2004;131:1607-18.

34. Sui G, Soohoo C, Affar el B, Gay F, Shi Y, Forrester WC, et al. A DNA vectorbased RNAi technology to suppress gene expression in mammalian cells. Proc Natl Acad Sci U S A. 2002;99:5515-20.

35. Glasgow SM, Henke RM, Macdonald RJ, Wright CV, Johnson JE. Ptf1a determines GABAergic over glutamatergic neuronal cell fate in the spinal cord dorsal horn. Development. 2005:132:5461-9.

36. Hoshino M, Nakamura S, Mori K, Kawauchi T, Terao M, Nishimura YV, et al. Ptfla, a bHLH transcriptional gene, defines GABAergic neuronal fates in cerebellum. Neuron. 2005;47:201-13.

37. Jusuf PR, Harris WA. Ptf1a is expressed transiently in all types of amacrine cells in the embryonic zebrafish retina. Neural Dev. 2009;4:34.

38. Wildner H, Das Gupta R, Brohl D, Heppenstall PA, Zeilhofer HU, Birchmeier C. Genome-wide expression analysis of Ptfla- and Ascl1-deficient mice reveals new markers for distinct dorsal horn interneuron populations contributing to nociceptive reflex plasticity. J Neurosci. 2013;33:7299-307.

39. Nishida K, Hoshino M, Kawaguchi Y, Murakami F. Ptf1a directly controls expression of immunoglobulin superfamily molecules Nephrin and Neph3 in the developing central nervous system. J Biol Chem. 2010;285:373-80.

40. Henke RM, Savage TK, Meredith DM, Glasgow SM, Hori K, Dumas J, et al. Neurog2 is a direct downstream target of the Ptf1a-Rbpj transcription complex in dorsal spinal cord. Development. 2009;136:2945-54.

41. Moser M, Pscherer A, Roth C, Becker J, Mucher G, Zerres K, et al. Enhanced apoptotic cell death of renal epithelial cells in mice lacking transcription factor AP-2 $\beta$. Genes Dev. 1997;11:1938-48.

42. Schorle $H$, Meier P, Buchert M, Jaenisch R, Mitchell PJ. Transcription factor AP-2 essential for cranial closure and craniofacial development. Nature. 1996;381:235-8.
43. Zhang J, Hagopian-Donaldson S, Serbedzija G, Elsemore J, Plehn-Dujowich D, McMahon AP, et al. Neural tube, skeletal and body wall defects in mice lacking transcription factor AP-2. Nature. 1996;381:238-41.

44. West-Mays JA, Zhang J, Nottoli T, Hagopian-Donaldson S, Libby D, Strissel $\mathrm{KJ}$, et al. AP-2a transcription factor is required for early morphogenesis of the lens vesicle. Dev Biol. 1999;206:46-62.

45. Aliferis K, Stoetzel C, Pelletier V, Helle S, Angioi-Duprez K, Vigneron J, et al. A novel TFAP2A mutation in familial Branchio-Oculo-Facial Syndrome with predominant ocular phenotype. Ophthalmic Genet. 2011;32:250-5.

46. Dumitrescu AV, Milunsky JM, Longmuir SQ, Drack AV. A family with branchiooculo-facial syndrome with primarily ocular involvement associated with mutation of the TFAP2A gene. Ophthalmic Genet. 2012;33:100-6.

47. Furukawa T, Mukherjee S, Bao ZZ, Morrow EM, Cepko CL. rax, Hes 1, and notch1 promote the formation of Müller glia by postnatal retinal progenitor cells. Neuron. 2000;26:383-94.

48. Marquardt T, Ashery-Padan R, Andrejewski N, Scardigli R, Guillemot F, Gruss P. Pax6 is required for the multipotent state of retinal progenitor cells. Cell. 2001;105:43-55.

49. Wu F, Li R, Umino Y, Kaczynski TJ, Sapkota D, Li S, et al. Onecut1 is essential for horizontal cell genesis and retinal integrity. J Neurosci. 2013;33:13053-65.

50. Poche RA, Kwan KM, Raven MA, Furuta Y, Reese BE, Behringer RR. Lim1 is essential for the correct laminar positioning of retinal horizontal cells. J Neurosci. 2007;27:14099-107

51. Dyer MA, Livesey FJ, Cepko CL, Oliver G. Prox1 function controls progenitor cell proliferation and horizontal cell genesis in the mammalian retina. Nat Genet. 2003;34:53-8.

52. Sapkota D, Chintala H, Wu F, Fliesler SJ, Hu Z, Mu X: Onecut1 and Onecut2 redundantly regulate early retinal cell fates during development. Proc Natl Acad Sci U S A. 2014;111:E4086-95.

53. Brown NL, Patel S, Brzezinski J, Glaser T. Math5 is required for retinal ganglion cell and optic nerve formation. Development. 2001;128:2497-508.

54. Wang SW, Kim BS, Ding K, Wang H, Sun D, Johnson RL, et al. Requirement for math5 in the development of retinal ganglion cells. Genes Dev. 2001;15:24-9.

55. Yang Z, Ding K, Pan L, Deng M, Gan L. Math5 determines the competence state of retinal ganglion cell progenitors. Dev Biol. 2003;264:240-54

56. Kawaguchi Y, Cooper B, Gannon M, Ray M, MacDonald RJ, Wright CV. The role of the transcriptional regulator Ptf1a in converting intestinal to pancreatic progenitors. Nat Genet. 2002;32:128-34.

57. Trapnell C, Roberts A, Goff L, Pertea G, Kim D, Kelley DR, et al. Differential gene and transcript expression analysis of RNA-seq experiments with TopHat and Cufflinks. Nat Protoc. 2012;7:562-78.

58. Sturn A, Quackenbush J, Trajanoski Z. Genesis: cluster analysis of microarray data. Bioinformatics. 2002;18:207-8.

59. da Huang W, Sherman BT, Lempicki RA. Systematic and integrative analysis of large gene lists using DAVID bioinformatics resources. Nat Protoc. 2009:4:44-57.

60. Jin K, Xiang M. In vitro explant culture and related protocols for the study of mouse retinal development. Methods Mol Biol. 2012;884:155-65.

\section{Submit your next manuscript to BioMed Central and take full advantage of:}

- Convenient online submission

- Thorough peer review

- No space constraints or color figure charges

- Immediate publication on acceptance

- Inclusion in PubMed, CAS, Scopus and Google Scholar

- Research which is freely available for redistribution 